\title{
CRESCIMENTO E NUTRIÇÃO DE ERVA-MATE INFLUENCIADOS PELA ADUBAÇÃO NITROGENADA, FOSFATADA E POTÁSSICA
}

\section{GROWTH AND NUTRITIONAL COMPOSITION OF ERVA-MATE AS AFFECTED BY NITROGEN, PHOSPHATE AND POTASSIUM FERTILIZATION}

\author{
Delmar Santin ${ }^{1}$ Eliziane Luiza Benedetti ${ }^{2}$ Marília Camotti Bastos ${ }^{3}$ Jéssica Fernandes Kaseker ${ }^{4}$ \\ Carlos Bruno Reissmann ${ }^{5}$ Gilvano Ebling Brondani ${ }^{6}$ Nairam Félix de Barros ${ }^{7}$
}

\section{RESUMO}

A ocorrência natural da erva-mate em solos ácidos e com baixa fertilidade natural, levou essa espécie a ser considerada de baixa exigência nutricional, principalmente em relação ao fósforo, embora pouco se conheça também sobre a exigência de N e K. Diante disto, o objetivo deste trabalho foi avaliar o crescimento, teor de nutrientes no solo e em plantas jovens de erva-mate submetidas a doses de $\mathrm{P}$ combinadas com NK. Aplicou-se 0, 100, 200, 400 e $600 \mathrm{mg} \mathrm{dm}^{-3} \mathrm{de}_{\mathrm{P}_{2}} \mathrm{O}_{5}$ combinados com 0, 50 e $100 \mathrm{mg} \mathrm{dm}^{-3}$ de $\mathrm{N} \mathrm{e} \mathrm{K}_{2} \mathrm{O}$ a um Latossolo Vermelho distrófico. Três mudas de erva-mate foram transplantadas para vasos com $2,9 \mathrm{dm}^{3}$ de solo. Aos 120 dias determinaram-se a altura, diâmetro do caule, comprimento e volume radicular e produção de matéria seca da parte aérea e radicular das mudas. Determinaram-se os teores de N, P, K, Ca, $\mathrm{Mg}, \mathrm{Fe}, \mathrm{Cu}, \mathrm{Zn}, \mathrm{Mn}$ e $\mathrm{Al}$ das folhas e raízes, além do conteúdo de N, P, K, Ca e Mg. Amostras de solo foram submetidas à análise química. $\mathrm{O}$ crescimento da erva-mate foi afetado pela interação entre $\mathrm{P}$ e $\mathrm{NK}$, demonstrando melhor crescimento quando o teor de $\mathrm{P}$ no solo estava entre 18,5 a 28,6 $\mathrm{mg} \mathrm{dm}^{-3}$ combinado com $100 \mathrm{mg} \mathrm{dm}^{-3}$ de $\mathrm{N}$ e $\mathrm{K}_{2} \mathrm{O}$. Em doses superiores a $400 \mathrm{mg} \mathrm{dm}^{-3} \mathrm{de}_{2} \mathrm{O}_{5}$, as folhas passaram a apresentar clorose internerval, sintoma típico de deficiência de Fe. A ordem dos macronutrientes mais exigidos e que mais contribuíram para o crescimento da erva-mate foi $\mathrm{P}, \mathrm{N}, \mathrm{K}, \mathrm{Mg}$ e Ca. A erva-mate cresce bem em solos com altos teores de $\mathrm{P}$, mas depende da boa disponibilidade de $\mathrm{N}, \mathrm{K}$ e Ca.

Palavras-chave: Ilex paraguariensis; interação nutricional; teor de nutrientes; raízes.

\section{ABSTRACT}

Ilex paraguariensis is considered a low P-requiring species because it grows naturally in soils with low $\mathrm{P}$ content, although no much information is also available for $\mathrm{N}$ and $\mathrm{K}$ requirements. This trial aimed to evaluate the effect of increasing $\mathrm{P}$ rates, combined with $\mathrm{N}$ and $\mathrm{K}$ rates on Ilex paraguariensis growth and its mineral composition. Phosphorus rates of 0,100, 200, 400 e $600 \mathrm{mg} \mathrm{dm}^{-3}$ of $\mathrm{P}_{2} \mathrm{O}_{5}$ were combined with 0 , 50 e $100 \mathrm{mg} \mathrm{dm}^{-3}$ of $\mathrm{Ne} \mathrm{K}_{2} \mathrm{O}$. The fertilizers were mixed with the soil and placed in plastic pots of $2.9 \mathrm{dm}^{3}$.

1. Engenheiro Florestal, Pós-doutorando do Programa de Pós-Graduação em Ciência do Solo da Universidade do Estado de Santa Catarina. Av. Luiz de Camões, CEP 88520-000, Lages (SC). Bolsista CNPq. desantinflorestal@yahoo.com.br

2. Engenheira Agrônoma, Dra. Professora do Instituto Federal de Santa Catarina - IFSC, Campus Canoinhas, Av. Expedicionários, Bairro Campo da Água Verde, CEP 89460-000, Canoinhas (SC). elibettiagro@yahoo.com.br

3. Engenheira Agrônoma, Doutoranda do Programa de Pós-Graduação em Ciência do Solo da Universidade Federal de Santa Maria, Campus - Bairro Camobi, CEP 97105-900, Santa Maria (RS). mcamotti@hotmail.com

4. Engenheira Agrônoma, Doutoranda do Programa de Pós-Graduação em Ciência do Solo da Universidade do Estado de Santa Catarina. Av. Luiz de Camões, CEP 88520-000, Lages (SC). jessikaseker@hotmail.com

5. Engenheiro Florestal, Dr. Professor Sênior do Programa de Pós-Graduação em Ciências do Solo, Universidade Federal do Paraná, Rua dos Funcionários, 1540, CEP 80035-050, Curitiba (PR). reissman@ufpr.br

6. Engenheiro Florestal, Dr. Professor do Departamento de Engenharia Florestal da Universidade Federal de Mato Grosso, Av. Fernando Corrêa da Costa, Bairro Boa Esperança, CEP 78060-900, Cuiabá (MT). gebrondani@yahoo.com.br

7. Engenheiro Florestal, Dr. Professor do Programa de Pós-graduação em Solos e Nutrição de Plantas, Universidade Federal de Viçosa, Av. P.H. Rolfs, s/n, Campus Universitário, CEP 36570-000, Viçosa (MG). Bolsista do CNPq. nfbarros@ufv.br

Recebido para publicação em 25/11/2010 e aceito em 28/11/2011 
Seedlings of Ilex were transplanted to the pots and grown for 120 days. Ilex seedling growth was affected by the interaction of $\mathrm{P}$ and NK rates. The best $\mathrm{P}$ rate was between 18.5 and $28.6 \mathrm{mg} \mathrm{dm}^{-3}$ and the highest growth was obtained when $\mathrm{P}$ was combined with $100 \mathrm{mg} \mathrm{dm}^{-3} \mathrm{O} \mathrm{N}_{\text {and }} \mathrm{K}_{2} \mathrm{O}$. Iron deficiency symptoms appeared at the $\mathrm{P}$ rates of 400 and $600 \mathrm{mg} \mathrm{dm}^{-3}$ of $\mathrm{P}_{2} \mathrm{O}_{5}$. It can be concluded that Ilex responds to increasing $\mathrm{P}$ rates, as long as plant $\mathrm{N}, \mathrm{K}$ and $\mathrm{Ca}$ requirement is met.

Keywords: Ilex paraguariensis; nutritional interaction; nutrient content; roots.

\section{INTRODUÇÃO}

A erva-mate (Ilex paraguariensis St. Hil.) é nativa da região Sul do Brasil e, além de ser usada no tradicional chimarrão e tereré, bebidas típicas de algumas regiões do país, também é matéria-prima para produção de medicamentos, cosméticos, produtos de higiene dentre outros (MACCARI e MAZUCHOWSKI, 2000). A ocorrência da erva-mate em solos com baixos teores disponíveis de $\mathrm{P}$, aliada ao baixo teor foliar deste nutriente, levou Reissmann et al. (1983) e Radomski et al. (1992) a considerá-la pouco exigente em $\mathrm{P}$. No entanto, a resposta positiva a doses de $\mathrm{P}$ e nulas e/ou negativas a doses de $\mathrm{N}$ e $\mathrm{K}$ (SANTIN et al., 2008) sugerem a possibilidade de resposta à $\mathrm{N}, \mathrm{P}$ e $\mathrm{K}$, quando testados conjuntamente em função das interações entre nutrientes. A interação é uma ação mútua ou recíproca de um elemento sobre o outro em relação ao crescimento das plantas, podendo ser de ordem sinérgica ou antagônica no solo (OLSEN, 1983) e competitiva e não competitiva na planta (MARSCHNER, 1995), o que pode ocasionar diferentes respostas.

No solo, principalmente nos mais argilosos e intemperizados, ricos em oxi-hidróxidos de $\mathrm{Fe}$ e $\mathrm{Al}$ com pH ácido, a adsorção de P é alta (ROLIM NETO et al., 2004), e até $90 \%$ do $\mathrm{P}$ aplicado pode assumir formas de reduzida labilidade (GONÇALVES et al., 1985; NOVAIS e SMYTH, 1999). Por outro lado, altos teores de $\mathrm{P}$ podem reduzir a disponibilidade de outros nutrientes, como é o caso do Fe e Zn (ABREU et al., 2007). No que se refere ao K, altos teores no solo podem inibir a absorção do Ca (ALVES et al., 1988) e Mg (FONSECA e MEURER, 1997). As interações do P com Zn, Fe e Cu (OLSEN, 1983) são normalmente antagônicas quando estes micronutrientes se encontram em baixos teores no solo (REDDY et al., 1978).

A capacidade de absorção e a eficiência de utilização de $\mathrm{P}$ pelas plantas são influenciadas por diferenças genotípicas dos vegetais (LUCA et al., 2002) e dependem da natureza, da concentração e interação de nutrientes na rizosfera (FAGERIA et al., 2009). Em solos deficientes em $P$, a assimilação de
N pelas plantas é limitada (RUFTY JR et al., 1990; ALVES et al., 1996) prejudicando seu metabolismo (MARSCHNER, 1995), no que tange, principalmente, à redução da absorção e translocação de $\mathrm{NO}_{3}^{-}$das raízes para a parte aérea e acúmulo deste na raiz (JESCHKE et al., 1997). O P e o N interagem de forma sinérgica e, em doses adequadas, promovem aumentos na produção vegetal (SHUMAN, 1994). Em espécies arbóreas como a grápia (Apuleia leiocarpa), $\mathrm{o}$ aumento do teor foliar de $\mathrm{N}$ pode ser favorecido pela interação de NP, PK e pela interação tripla de NPK (NICOLOSO et al., 2007).

Em espécies florestais, normalmente os nutrientes mais limitantes ao crescimento são o $\mathrm{N}$ e o P (VENTURIN et al., 1996), bem como os mais exigidos (VENTURIN et al., 1999). Espécies com crescimento lento, adaptadas a solos de baixa fertilidade, têm baixa eficiência de utilização e são menos responsivas ao fornecimento de nutrientes (LAMBERS e POORTER, 1992). Mudas de erva-mate responderam positivamente a P (SANTIN et al., 2008) e, em solo pobre no nutriente, o crescimento foi beneficiado até a dose de $447,5 \mathrm{mg} \mathrm{kg}^{-1}$ de P. Por outro lado, doses isoladas de $\mathrm{Ne} \mathrm{K}$ superiores a $100 \mathrm{mg} \mathrm{kg}^{-1}$ mostraram ação depressiva sobre as mudas. $\mathrm{O}$ desbalanço de nutrientes no solo é um dos principais fatores limitantes ao crescimento vegetal (MORTVEDT e KHASAWNEH, 1986), por afetar o metabolismo das plantas (DECHEN e NACHTIGALL, 2007).

O conhecimento sobre a nutrição e respostas da erva-mate à adubação ainda é restrito. Por isso, o objetivo desse trabalho foi avaliar a influência da adubação fosfatada, combinada com a nitrogenada e potássica, no crescimento, teor de nutrientes no solo e em plantas jovens de erva-mate.

\section{MATERIAIS E MÉTODOS}

O experimento, instalado em julho de 2007, foi conduzido em casa de vegetação da UFPR em Curitiba - PR. Na casa de vegetação havia controle de temperatura (máxima de $32{ }^{\circ} \mathrm{C}$ ), mas não de umidade. No estudo utilizaram-se mudas de erva-mate (Ilex 
paraguariensis St. Hil.) propagadas por sementes de matrizes nativas do município de São Mateus do Sul PR. A produção das mudas foi realizada no viveiro da Empresa Baldo S/A do mesmo município.

Os tratamentos foram compostos por combinações de doses de $\mathrm{P}(0,100,200$, 400 e $600 \mathrm{mg} \mathrm{dm}^{-3}$ de $\left.\mathrm{P}_{2} \mathrm{O}_{5}\right)$ com $\mathrm{N}$ e $\mathrm{K}(0$, 50 e $100 \mathrm{mg} \mathrm{dm}^{-3}$ de $\mathrm{Ne} \mathrm{K}_{2} \mathrm{O}$ ). Os tratamentos foram arranjados em esquema fatorial ( $5 \times 3)$, com cinco doses de $\mathrm{P}$ três de NK, dispostos no delineamento blocos casualizados com quatro repetições. Cada unidade experimental foi composta por um vaso com $2,9 \mathrm{dm}^{-3} \mathrm{de}$ solo contendo três mudas de erva-mate.

As fontes de $\mathrm{P}, \mathrm{N}$ e $\mathrm{K}$ foram, respectivamente, superfosfato triplo, ureia e cloreto de potássio, as quais foram incorporadas e homogeneizadas ao solo na instalação do experimento. Quando as mudas apresentaram altura média de aproximadamente $5 \mathrm{~cm}$, três foram transferidas para vaso de polietileno de $15,5 \mathrm{~cm}$ de altura com capacidade de $3 \mathrm{dm}^{3}$, contendo $2,9 \mathrm{dm}^{-3}$ de Latossolo Vermelho distrófico, com densidade de $1 \mathrm{~kg} \mathrm{dm}^{-3}$, coletado em plantio de erva-mate na profundidade de 0 a $20 \mathrm{~cm}$ (Tabela 1).

As mudas foram irrigadas com água desionizada, conforme a necessidade. Após 120 dias da instalação do experimento, determinaram-se a altura total (HT); diâmetro do colo (DC); comprimento (CR) e volume radicular (VR); massa seca aérea (MAS (folha+caule)), radicular (MSR) e total (MST (folha+caule + raiz)); teor e conteúdo de elementos na folha e raiz da planta.

A HT foi medida com régua $(\mathrm{cm})$ do nível do solo ao ápice das plantas e, o DC, medido com paquímetro $(\mathrm{mm})$ a $0,5 \mathrm{~cm}$ do solo. O VR e CR das raízes foram obtidos através de scanner acoplado ao software Whin Rhizo, marca LA 1600 e versão 98. Para determinação da massa seca, o material vegetal foi separado em parte aérea (folha e caule) e radicular, lavado e seco em estufa a $65^{\circ} \mathrm{C}$, até peso constante. Após pesados cada compartimento, as folhas e raízes foram moídas e submetidas à determinação de $\mathrm{P}, \mathrm{K}, \mathrm{Ca}$, $\mathrm{Mg}, \mathrm{Fe}, \mathrm{Cu}, \mathrm{Zn}, \mathrm{Mn}, \mathrm{Al}$ (MARTINS e REISSMANN, 2007) e N-total (BREMNER, 1996), permitindo obter o teor foliar e radicular desses elementos. De posse desses dados, determinou-se o conteúdo de N, P, K, $\mathrm{Ca}$ e $\mathrm{Mg}$ na massa seca de folha e raiz.

No solo, após o cultivo, determinaram-se os teores de $\mathrm{P}, \mathrm{K}, \mathrm{Ca}, \mathrm{Mg}, \mathrm{Fe}, \mathrm{Cu}, \mathrm{Zn}, \mathrm{Mn}$ e Al, conforme metodologia descrita por Embrapa (1997). Para avaliar o efeito das doses no teor de elementos no solo e na planta, crescimento e conteúdo de N, P, K, Ca e $\mathrm{Mg}$ na folha, raiz e folha+raiz os dados foram submetidos à análise de variância $(\mathrm{p}<0,05)$ e de regressão $(\mathrm{p}<0,05)$ usando-se o software SISVAR (FERREIRA, 2008). Para entender melhor a atuação do N, P, K, Ca e Mg no crescimento das plantas, correlacionaram-se as variáveis de crescimento com o conteúdo destes elementos na massa de folha, raiz e na folha+raiz.

\section{RESULTADOS E DISCUSSÃO}

\section{Características químicas do solo}

Os teores no solo de $\mathrm{P}, \mathrm{Ca}, \mathrm{Fe}$ (Figuras 1A e $\mathrm{C}), \mathrm{Cu}$ (Tabela 2) e a recuperação de $\mathrm{P}$ foram alterados apenas pelas doses de $\mathrm{P}_{2} \mathrm{O}_{5}$. Já os teores no solo de K, Zn (Figura 1B e D), Mg e Mn (Tabela 2) foram afetados pela interação das doses de $\mathrm{P}$ com as de NK. Somente o teor de $\mathrm{Al}$ no solo não foi significativamente afetado pelos tratamentos.

$\mathrm{O}$ teor de $\mathrm{P}$ no solo aumentou com as doses de $\mathrm{P}_{2} \mathrm{O}_{5}$ aplicadas, passando de 1,9 para $43,0 \mathrm{mg} \mathrm{dm}^{-3}$. A recuperação de P pelo extrator Mehlich-1 foi de 7,4 \% na dose de $100 \mathrm{mg} \mathrm{dm}^{-3} \mathrm{de}_{2} \mathrm{O}_{5}$, passando para $15,1 \%$ na dose de $600 \mathrm{mg} \mathrm{dm}^{-3} \mathrm{de}_{2} \mathrm{O}_{5}$ (Figura 1A). Houve estreita relação entre as doses de $\mathrm{P}$ e o teor do nutriente recuperado. Normalmente, em solos argilosos e oxídicos a capacidade de adsorção de $\mathrm{P}$ proveniente de fontes solúveis é alta (GONÇALVES et al., 1985; GONÇALVES et al., 1989; NOVAIS e SMYTH, 1999), como verificado neste trabalho. O teor de $P$ disponível no solo atingiu valores considerados muito altos, já a partir da dose de $216,7 \mathrm{mg} \mathrm{dm}^{-3}$ de $\mathrm{P}_{2} \mathrm{O}_{5}$ (SBCS, 2004).

$\mathrm{O}$ teor de $\mathrm{K}$ no solo aumentou com as doses de $\mathrm{N}$ e $\mathrm{K}$ (Figura 1B), passando de nível médio para alto (SBCS, 2004) na dose de $0 \mathrm{mg} \mathrm{dm}^{-3} \mathrm{de}_{2} \mathrm{O}_{5}$. Porém, quando doses de $\mathrm{P}$ foram combinadas com as de 50 e $100 \mathrm{mg} \mathrm{dm}^{-3}$ de $\mathrm{Ne} \mathrm{K}_{2} \mathrm{O}$

TABELA 1: Caracterização química e teor de argila do Latossolo Vermelho distrófico utilizado como substrato

TABLE 1: Soil chemical and physical characteristics.

\begin{tabular}{cccccccccccc}
\hline $\mathrm{pH}$ & $\mathrm{Ca}$ & $\mathrm{Mg}$ & $\mathrm{Al}$ & $\mathrm{H}+\mathrm{Al}$ & $\mathrm{T}$ & $\mathrm{V}$ & $\mathrm{m}$ & $\mathrm{C}$ & $\mathrm{P}$ & $\mathrm{K}$ & Argila \\
\hline $\mathrm{CaCl}_{2}$ & $\ldots \ldots \ldots \ldots \ldots \ldots \ldots \ldots \mathrm{cmol}_{\mathrm{c}} \mathrm{dm}^{-3} \ldots \ldots \ldots \ldots \ldots \ldots \ldots$ & $\ldots \ldots \ldots . \ldots \ldots \ldots$ & $\mathrm{g} \mathrm{dm}^{-3}$ & $\ldots . \mathrm{mg} \mathrm{dm}^{-3} \ldots$ & $\%$ \\
3,9 & 0,3 & 0,2 & 4,5 & 14,1 & 14,7 & 4 & 88 & 34,1 & 2,1 & 50,8 & 75 \\
\hline
\end{tabular}



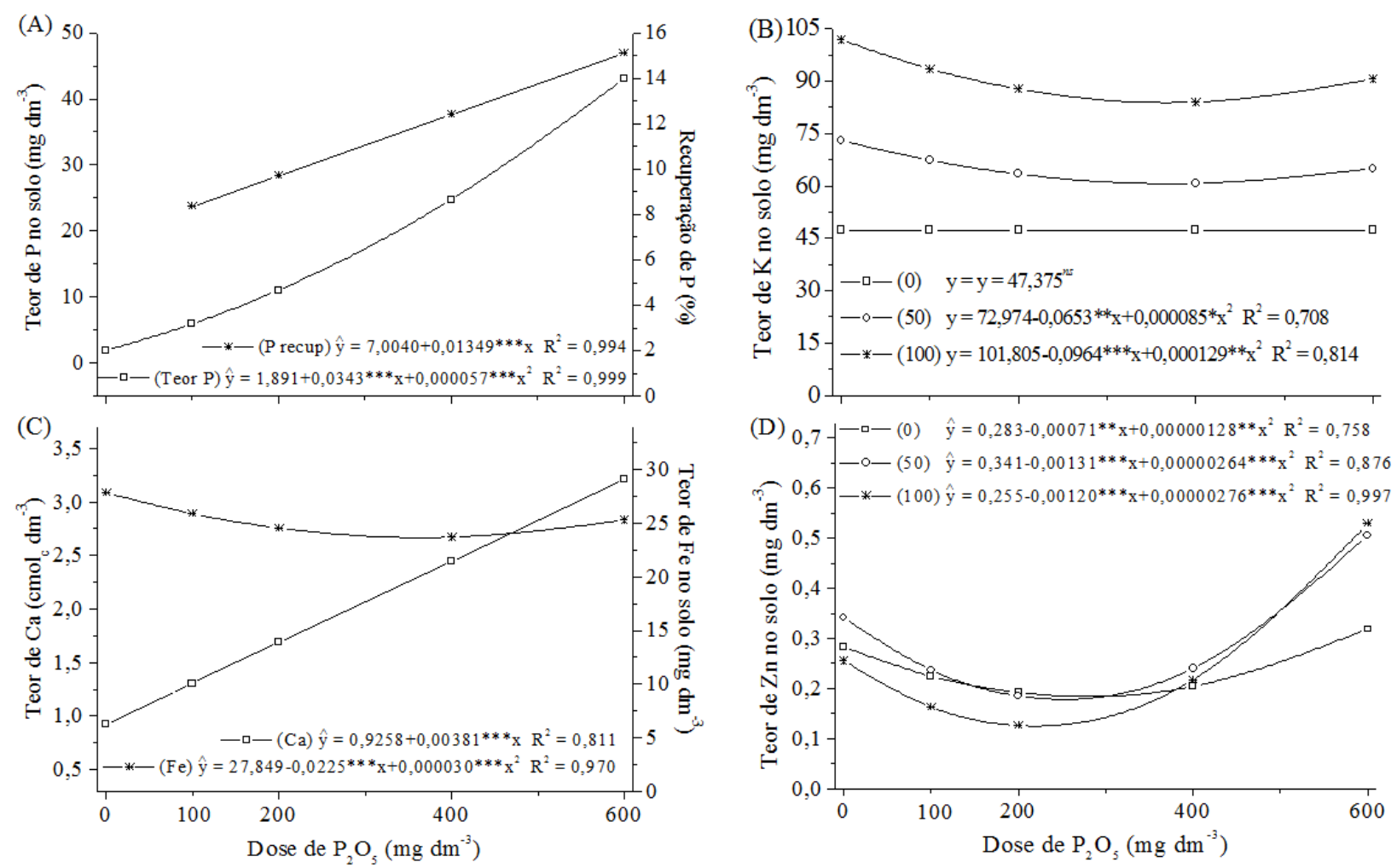

FIGURA 1: Teor e recuperação de $\mathrm{P}(\mathrm{A})$ e teor de $\mathrm{Ca}$ e $\mathrm{Fe}(\mathrm{C})$ em função das doses de $\mathrm{P}$; teor de $\mathrm{K}$ (B) e $\mathrm{Zn}$ (D) nas doses de 0,50 e $100 \mathrm{mg} \mathrm{dm}^{-3}$ de $\mathrm{N} \mathrm{e} \mathrm{K}_{2} \mathrm{O}$ em função das doses de $\mathrm{P}$ em solo cultivado com plantas jovens de Ilex paraguariensis. ${ }^{*}, * *, * * *$ significativo respectivamente a $5 ; 1$; $0,1 \% \mathrm{e}^{\text {ns }}$ não significativo.

FIGURE 1: Soil $\mathrm{P}$ content and extract ant $\mathrm{P}(\mathrm{A})$ rate and soil content of $\mathrm{Ca}$ and $\mathrm{Fe}(\mathrm{C})$ as affected by $\mathrm{P}$; $\mathrm{K}$ content (B) and $\mathrm{Zn}$ (D) as affected by $\mathrm{P}$ and NK rates applied to the soil cultivated with Ilex paraguariensis. ${ }^{*}, * *, * * *$ Significant respectively to the $5 ; 1 ; 0,1 \%$ levels and ${ }^{\text {ns }}$ nosignificant.

TABELA 2: Equação de regressão para o teor de $\mathrm{Mg}$, Cu e Mn no solo em função das doses de P combinadas com NK em solo cultivado com plantas jovens de Ilex paraguariensis

TABLE 2: Regression equations relating soil $\mathrm{Mg}, \mathrm{Cu}$, and $\mathrm{Mn}$ content with $\mathrm{P}$ and $\mathrm{NK}$ rates applied to the soil cultivated with Ilex paraguariensis.

\begin{tabular}{|c|c|c|c|}
\hline Variável & Dose de NK $\left(\mathrm{mg} \mathrm{dm}^{3}\right)$ & Equação de regressão ${ }^{1 /}$ & $\mathrm{R}^{2}$ \\
\hline \multirow{3}{*}{$\mathrm{Mg}$} & 0 & $\hat{\mathrm{y}}=0,0999+0,000054 * * * \mathrm{x}$ & 0,678 \\
\hline & 50 & $\hat{\mathrm{y}}=0,1037+0,000040^{* *} \mathrm{x}$ & 0,603 \\
\hline & 100 & $\hat{y}=0,1092+0,000023 * x$ & 0,803 \\
\hline \multirow{3}{*}{$\mathrm{Mn}$} & 0 & $\hat{y}=26,148-0,0878 * * x+0,000354 * * x^{2}-0,000000347 * * x^{3}$ & 0,999 \\
\hline & 50 & $\hat{y}=\bar{y}=23,602^{\text {ns }}$ & ----- \\
\hline & 100 & $\hat{y}=26,089-0,0520 * x+0,000212 * x^{2}-0,000000202 * x^{3}$ & 0,437 \\
\hline $\mathrm{Cu}$ & Doses de $\mathrm{P}^{2 /}$ & $\hat{\mathrm{y}}=1,241-0,00021 * * * \mathrm{x}$ & 0,923 \\
\hline
\end{tabular}

Em que: ${ }^{1 *}, * *, * * *$ significativo respectivamente a $5 ; 1 ; 0,1 \% \mathrm{e}^{\text {ns }}$ não significativo $\mathrm{e}^{2 /}$ sem interação entre doses de $\mathrm{P}$ e NK. 
o teor de $\mathrm{K}$ no solo reduziu. Os teores mínimos foram de 60,4 e $83,8 \mathrm{mg} \mathrm{dm}^{-3}$ de $\mathrm{K}$, respectivamente, nas doses de 384 e $374 \mathrm{mg} \mathrm{dm}^{-3}$ de $\mathrm{P}_{2} \mathrm{O}_{5}$, caracterizando interação antagônica de $\mathrm{P}$ e K.

Os teores de $\mathrm{Ca}$ (Figura 1C) e Mg (Tabela 2) aumentaram linearmente com a adição de P. No entanto, a combinação do P com o NK reduziu de forma branda o teor de $\mathrm{Mg}$ no solo com o aumento das doses de P. Para o Ca ocorreu mudança na classe de fertilidade do solo de baixa para média (SBCS, 2004) pela aplicação do superfosfato triplo.

As doses de $\mathrm{P}$ afetaram negativamente os teores de $\mathrm{Fe}$ e $\mathrm{Cu}$ no solo. $\mathrm{O}$ teor de $\mathrm{Cu}$ foi reduzido linearmente (Tabela 2) e o mínimo de Fe chegou a $23,6 \mathrm{mg} \mathrm{dm}^{-3}$ na dose de $375 \mathrm{mg} \mathrm{dm}^{-3} \mathrm{de}_{\mathrm{P}_{2}} \mathrm{O}_{5}$ (Figura 1C). A disponibilidade de $\mathrm{Zn}$ (Figura 1D) e $\mathrm{Mn}$ (Tabela 2) foi afetada pela interação de NK com o P.

A ação depressiva do $P$ na disponibilidade de Fe no solo se deve principalmente pelo desequilíbrio de teores com o aumento das doses de P (REDDY et al., 1978), sendo, principalmente, em solos ácidos a precipitação de $\mathrm{Fe}$ na forma de $\mathrm{FePO}_{4}^{-}$uma das causas de sua baixa disponibilidade (DECHEN e NACHTIGALL, 2007). Para o Zn, quando os teores de $P$ se situavam na faixa entre 12,0 e $15,8 \mathrm{mg} \mathrm{dm}^{-3} \mathrm{a}$ interação do $\mathrm{Pe}$ NK com o $\mathrm{Zn}$ foi antagônica e, com o aumento do teor de $\mathrm{P}$ no solo, a mesma foi sinérgica, aumentando o teor de $\mathrm{Zn}$. Quando o teor de P e Zn se situam em faixas normais, não se esperam fortes interações destes nutrientes (LORENAGAN, 1993), sendo que, em alguns casos, a aplicação de $\mathrm{P}$ pode aumentar a disponibilidade de Zn (SHUMAN, 1988). Mesmo para solos com teores adequados de micronutrientes, deve-se ter cautela nas doses de fosfato, pois a interação do $\mathrm{P}$, especialmente com o $\mathrm{Fe} \mathrm{e} \mathrm{Cu}$, poderá afetar a disponibilidade destes às plantas.

\section{Crescimento das plantas}

Das características de crescimento, apenas o DC e a MSR não foram afetadas pela interação do $P$ com o NK (Figura 2A). O comportamento foi quadrático positivo para todas as características de crescimento analisadas, em função das doses de $\mathrm{P}$ testadas.

$\mathrm{O}$ máximo crescimento do DC ocorreu na dose de $384 \mathrm{mg} \mathrm{dm}^{-3}$ de $\mathrm{P}_{2} \mathrm{O}_{5}$ (Figura 2A). Para a altura, houve efeito aditivo das doses de NK em relação à resposta às doses de $\mathrm{P}$. A altura máxima de $27,9,30,3$ e $32,1 \mathrm{~cm}$ foi obtida, respectivamente, com as doses de 384,387 e $395 \mathrm{mg} \mathrm{dm}^{-3}$ de $_{2} \mathrm{O}_{5}$ e 0 , 50 e $100 \mathrm{mg} \mathrm{dm}^{-3}$ de $\mathrm{N}$ e $\mathrm{K}_{2} \mathrm{O}$ (Figura $2 \mathrm{~B}$ ), evidenciando a resposta da erva-mate, não apenas ao $\mathrm{P}$, mas também ao NK.
O comprimento máximo de $8,43 \mathrm{~m}$ de raiz ocorreu na dose de $318 \mathrm{mg} \mathrm{dm}^{-3} \mathrm{de}_{2} \mathrm{O}_{5}$, quando aplicado conjuntamente com $100 \mathrm{mg} \mathrm{dm}^{-3}$ de $\mathrm{N} \mathrm{e} \mathrm{K}_{2} \mathrm{O}$ (Figura 2 C). Para essa mesma dose de $\mathrm{Ne} \mathrm{K}_{2} \mathrm{O}$, também se observou o volume máximo de $11,8 \mathrm{~cm}^{3}$ de raiz na dose de $420,4 \mathrm{mg} \mathrm{dm}^{-3}$ de $\mathrm{P}_{2} \mathrm{O}_{5}$ (Figura $2 \mathrm{D}$ ). A necessidade de menores teores de $\mathrm{P}\left(18,1 \mathrm{mg} \mathrm{dm}^{-3}\right)$ para maximizar o comprimento radicular (CR) na maior dose de NK mostra a importância da adubação conjunta de $\mathrm{P}, \mathrm{N}$ e K para essa variável. Plantas cultivadas com baixos teores de nutrientes tendem a investir mais energia na produção de raízes para aumentar a absorção dos mesmos (ZONTA et al., 2006). Quando o teor de $\mathrm{P}$ no solo era muito alto, as raízes eram mais grossas, o que reduziu a área de contato e, consequentemente, a absorção de nutrientes. Isto foi verificado no tratamento em que as maiores doses de $\mathrm{P}_{2} \mathrm{O}_{5}, \mathrm{~N} \mathrm{e} \mathrm{K}_{2} \mathrm{O}$ foram aplicadas, observando-se concomitantemente, o menor CR (Figura 2C) e maior VR (Figura 2D).

A produção máxima de MSR ocorreu na dose de $407 \mathrm{mg} \mathrm{dm}^{-3}$ de $\mathrm{P}_{2} \mathrm{O}_{5}$ (Figura 2A). As doses de $\mathrm{P}$ para as quais ocorreu a máxima produção de MSA e MST, nas três doses de NK, foram semelhantes, sendo, respectivamente, 447, 400 e $372 \mathrm{mg} \mathrm{dm}^{-3} \mathrm{de}_{2} \mathrm{O}_{5} \mathrm{e}$ 439, 402 e $389 \mathrm{mg} \mathrm{dm}^{-3}$ de $\mathrm{P}_{2} \mathrm{O}_{5}$ (Figuras 2E e F).

Em condições limitantes de suprimento de $\mathrm{P}$, as raízes de algumas espécies florestais podem ser drenos preferenciais de fotossintatos, se comparadas com a parte aérea (FERNANDES et al., 2000), sendo o CR favorecido em solos deficientes em nutrientes, notadamente em N e em P (MARSCHNER, 1995). Isto teria ocorrido neste experimento, visto que o CR da erva-mate foi menor em menores doses de $\mathrm{P}$ quando as plantas estavam bem supridas em $\mathrm{N}$ e $\mathrm{K}$ (Figura $2 \mathrm{C}$, dose de $100 \mathrm{mg} \mathrm{dm}^{-3}$ de $\mathrm{N}$ e $\mathrm{K}_{2} \mathrm{O}$ ), em comparação com as doses que maximizaram o crescimento em DC, HT e MSA (Figuras 2A, B e E).

$O$ fato da erva-mate, na maioria das vezes, ser considerada uma espécie que cresce bem em solos de baixa fertilidade (CARVALHO, 2003) e pouco exigente em P (REISSMANN et al., 1983; RADOMSKI et al., 1992), não significa que esta não responda à fertilização. Neste trabalho, a resposta da erva-mate ao $\mathrm{P}$ demonstra que a espécie é exigente neste nutriente, sendo a magnitude da resposta condicionada à disponibilidade de $\mathrm{N}, \mathrm{K}$ e sem descartar a do $\mathrm{Ca}$, que, por sua presença no superfosfato triplo, o solo teve seu teor aumentado. Santin et al. (2008), ao testarem doses individuais de N, P e K em erva-mate, observaram o melhor desempenho das mudas para as variáveis de crescimento na dose de $447 \mathrm{mg} \mathrm{kg}^{-1}$ de P. Por outro 

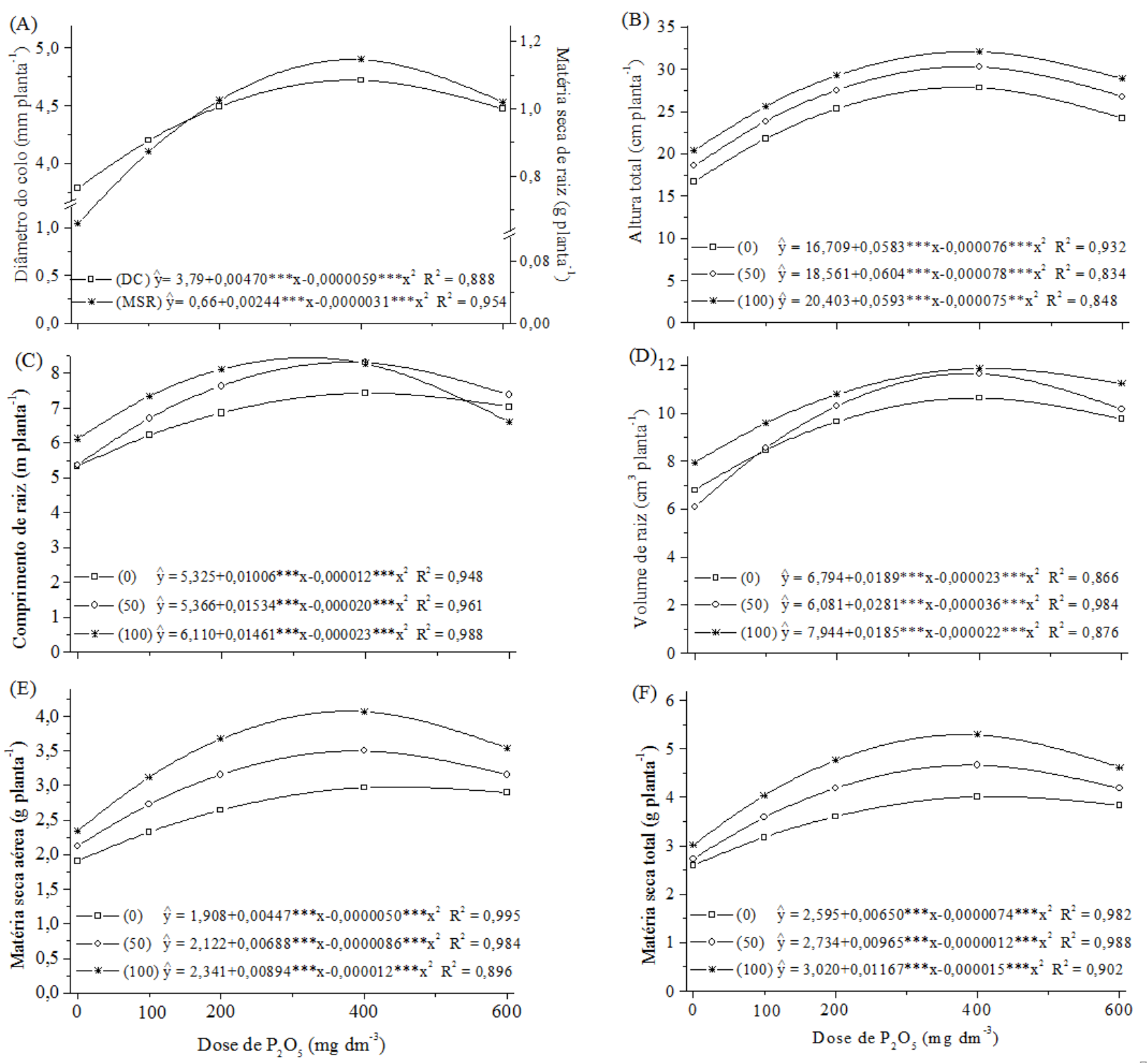

FIGURA 2: Características de crescimento de plantas jovens de Ilex paraguariensis em função das doses de P e NK. Diâmetro do colo e matéria seca de raiz (A), altura total (B), comprimento de raiz $(\mathrm{C})$, volume de raiz $(\mathrm{D})$, matéria seca aérea $(\mathrm{E})$, matéria seca total $(\mathrm{F}) .{ }^{* *},{ }^{* * *}$ significativo respectivamente a $1 ; 0,1 \% \mathrm{e}^{\text {ns }}$ não significativo.

FIGURE 2: Growth characteristics of Ilex paraguariensis seedlings as affected by P and NK rates. Seedling stem diameter and root dry matter (A); height (B), root length (C), root volume (D), shoot dry matter $(\mathrm{E})$ and seedling total dry weight $(\mathrm{F}) . * *, * * *$ Significant respectively to the $1 ; 0,1 \%$ levels and ${ }^{\text {ns }}$ no-significant.

lado, os mesmos autores, para as mesmas variáveis, constataram efeito negativo do $\mathrm{N}$ e $\mathrm{K}$ já na dose de $100 \mathrm{mg} \mathrm{kg}^{-1}$. A resposta positiva da erva-mate ao $\mathrm{N} \mathrm{e}$ $\mathrm{K}$ neste trabalho, demonstra a importância de se testarem doses conjuntas de $\mathrm{N}, \mathrm{P}$ e $\mathrm{K}$ que favoreçam o equilíbrio destes no solo, permitindo que as plantas demonstrem seu potencial de crescimento.

\section{Composição química da massa vegetal}

Somente as doses de $\mathrm{P}$ influenciaram o teor foliar de P, N, Fe (Figura 3A, C e F) e Mg (Tabela 3); teor radicular de K, Fe (Figura 3B e F), $\mathrm{Cu}$ e Al (Tabela 3); e conteúdo de $\mathrm{Ca}$ e $\mathrm{Mg}$ (Figura 4D). Mas a interação das doses de $\mathrm{P}$ com as de NK afetaram o teor foliar de $\mathrm{K}, \mathrm{Ca}, \mathrm{Zn}$ (Figura 

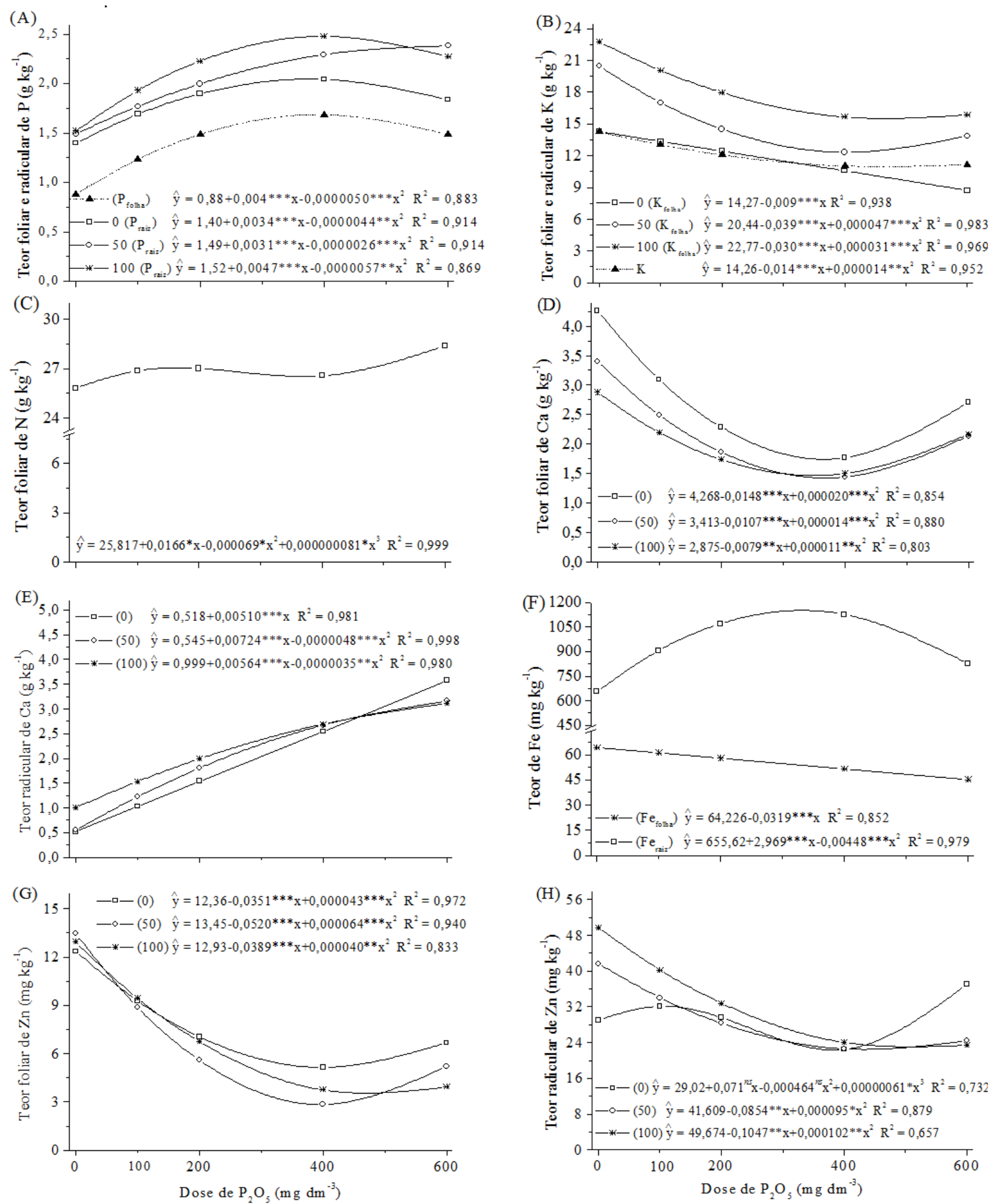

FIGURA 3: Composição química de plantas jovens de Ilex paraguariensis em função das doses de $\mathrm{P}$ e NK. Teor foliar e radicular de P (A), K (B) e Fe (F); teor foliar de N (C), Ca (D) e Zn (G); e teor radicular de $\mathrm{Ca}(\mathrm{E})$ e de $\mathrm{Zn}(\mathrm{H})$ em plantas jovens de erva-mate (Ilex paraguariensis St. Hil.) submetidas a doses de $\mathrm{P}$ combinadas com NK. *, **,*** significativo respectivamente a $5 ; 1$; $0,1 \% \mathrm{e}^{\text {ns }}$ não significativo.

FIGURE 3: Chemical composition of Ilex paraguariensis seedlings as affected by $\mathrm{P}$ and NK fertilization. Leaf and root contents of P (A); K (B) and Fe (F); leaf content of N (C), Ca (D) and Zn (G), and root content of $\mathrm{Ca}(\mathrm{E})$ and $\mathrm{Zn}(\mathrm{H}) .{ }^{*}, * *, * * *$ significant respectively at the $5 ; 1 ; 0,1 \%$ levels and ${ }^{\text {ns }}$ non-significant. 
TABELA 3: Equação de regressão para o teor foliar de $\mathrm{Cu}, \mathrm{Mn}, \mathrm{Mg}$ e $\mathrm{N}$ e teor radicular de $\mathrm{Mg}, \mathrm{Mn}, \mathrm{Cu}$, $\mathrm{Al}, \mathrm{N}$ e $\mathrm{K}$ em plantas jovens de erva-mate (Ilex paraguariensis) submetidas a doses de $\mathrm{P}$ combinadas com NK

TABLE 3: Regression equations relating Ilex paraguariensis leaf $\mathrm{Cu}, \mathrm{Mn}, \mathrm{Mg}$, and $\mathrm{N}$ content, and root $\mathrm{Mg}, \mathrm{Mn}, \mathrm{Cu}, \mathrm{Al}, \mathrm{N}$ and $\mathrm{K}$ content with $\mathrm{P}$ and $\mathrm{NK}$ rates.

\begin{tabular}{|c|c|c|c|c|}
\hline Variável & Eleme & to $\left(\mathrm{mg} \mathrm{dm}^{3}\right)$ & Equação de regressão ${ }^{1 /}$ & $\mathrm{R}^{2}$ \\
\hline \multirow{3}{*}{$\operatorname{Mg}$ (raiz) } & \multirow{10}{*}{ 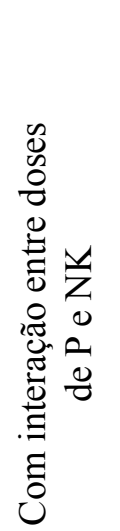 } & 0 & $\hat{\mathrm{y}}=1,124+0,00073 * * x$ & 0,703 \\
\hline & & 50 & $\hat{y}=\bar{y}=1,084^{\text {ns }}$ & ---- \\
\hline & & 100 & $\hat{y}=1,398-0,00228 * * x+0,0000031 * x^{2}$ & 0,908 \\
\hline \multirow{3}{*}{$\mathrm{Cu}$ (folha) } & & 0 & $\hat{\mathrm{y}}=12,135-0,0249 * * * x+0,000035^{* *} \mathrm{x}^{2}$ & 0,534 \\
\hline & & 50 & $\hat{y}=14,020-0,0294 * * * x+0,000034 * * x^{2}$ & 0,544 \\
\hline & & 100 & $\hat{\mathrm{y}}=13,182-0,0400 * * * \mathrm{x}+0,000053 * * * \mathrm{x}^{2}$ & 0,928 \\
\hline \multirow{3}{*}{ Mn (folha) } & & 0 & $\hat{y}=1086,45-4,769 * * x+0,02132 * * x^{2}-0,000022 * * x^{3}$ & 0,609 \\
\hline & & 50 & $\hat{y}=738,11+1,508 * x-0,00120^{n s} x^{2}$ & 0,938 \\
\hline & & 100 & $\hat{y}=748,26+2,497 * * x-0,00314 * * x^{2}$ & 0,907 \\
\hline \multirow{3}{*}{ Mn (raiz) } & & 0 & $\hat{y}=\bar{y}=383,63^{\text {ns }}$ & ---- \\
\hline & & 50 & $\hat{y}=704,37-2,1723 * * x+0,00282 * x^{2}$ & 0,683 \\
\hline & & 100 & $\hat{y}=743,91-6,5730 * * x+0,02290 * * x^{2}-0,000021 * * x^{3}$ & 0,946 \\
\hline $\mathrm{Mg}$ (folha) & \multirow{7}{*}{ 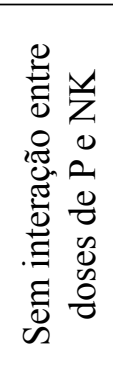 } & \multirow{3}{*}{ Doses de $\mathrm{P}$} & $\hat{\mathrm{y}}=2,872-0,0109 * * * x+0,000038^{* *} \mathrm{x}^{2}-0,000000036 * \mathrm{x}^{3}$ & 0,895 \\
\hline $\mathrm{Cu}($ raiz $)$ & & & $\hat{y}=79,770-0,2385 * * * x+0,000291 * * * x^{2}$ & 0,901 \\
\hline $\mathrm{Al}$ (raiz) & & & $\hat{y}=522,59+0,6468 * * * x$ & 0,962 \\
\hline $\mathrm{N}$ (folha) & & \multirow{4}{*}{$\begin{array}{c}\text { Doses de N } \\
\text { e K }\end{array}$} & $\hat{\mathrm{y}}=24,166+0,0552 * * * \mathrm{x}$ & 0,980 \\
\hline $\mathrm{N}$ (raiz) & & & $\hat{y}=17,483+0,0120 * x$ & 0,733 \\
\hline $\mathrm{K}$ (raiz) & & & $\hat{y}=9,569+0,0548 * * * x$ & 0,992 \\
\hline $\mathrm{Mg}$ (folha) & & & $\hat{y}=2,480-0,0039 * x$ & 0,892 \\
\hline
\end{tabular}

Em que: ${ }^{1 / *}, * *, * * *$ significativo respectivamente a $5 ; 1 ; 0,1 \% \mathrm{e}^{\text {ns }}$ não significativo.

3B, D e G), Cu e Mn (Tabela 3); radicular de P, $\mathrm{Ca}, \mathrm{Zn}$ (Figura 3A, E e H), Mg e Mn (Tabela 3); e conteúdo de N, P e K (Figura 4A, B e C). Para o teor foliar de $\mathrm{N}$ e $\mathrm{Mg}$ e teor radicular de $\mathrm{N}$ e $\mathrm{K}$, além da significância isolada das doses de $\mathrm{P}$, também foram significativas as doses de NK (Tabela 3).

$\mathrm{O}$ comportamento do teor máximo de $\mathrm{P}$ nos órgãos da erva-mate foi semelhante, sendo na folha $1,7 \mathrm{~g} \mathrm{~kg}^{-1}$ (na dose de $100 \mathrm{mg} \mathrm{dm}^{-3} \mathrm{de}$ $\mathrm{N}$ e $\mathrm{K}_{2} \mathrm{O}$ ) e na raiz $2,5 \mathrm{~g} \mathrm{~kg}^{-1}$, respectivamente na dose de 400 e $410 \mathrm{mg} \mathrm{dm}^{-3}$ de $\mathrm{P}_{2} \mathrm{O}_{5}$ (Figura 3A). Considerando que o teor foliar é o indicativo mais utilizado do estado nutricional de plantas (MARSCHNER, 1995), para a erva-mate é possível verificar teores foliares de $\mathrm{P}$ desde $0,8 \mathrm{~g} \mathrm{~kg}^{-1}$ (SOUZA et al., 2008) até $3,0 \mathrm{~g} \mathrm{~kg}^{-1}$ (WISNIEWSKI et al., 1996). Neste trabalho o teor foliar de P variou de 0,9 a $1,7 \mathrm{~g} \mathrm{~kg}^{-1}$, quando aplicadas doses, respectivamente, de 0 e $400 \mathrm{mg} \mathrm{dm}^{-3}$ de $\mathrm{P}_{2} \mathrm{O}_{5}$, que correspondem, de acordo com SBCS (2004), ao nível muito baixo $\left(1,9 \mathrm{mg} \mathrm{dm}^{-3}\right)$ e muito alto $\left(24,7 \mathrm{mg} \mathrm{dm}^{-3}\right)$ de P no solo (Figura 1A). Esse comportamento pode explicar até então, o porquê de alguns pesquisadores (REISSMANN et al., 1983; RADOMSKI et al., 1992) considerarem a erva-mate uma espécie pouco exigente em P. No entanto, esses resultados, juntamente aos verificados por Santin et al. (2008), demonstram que a erva-mate cresce bem em condições de altos teores de P no solo, já que mesmo na maior dose (teor de $43,0 \mathrm{mg} \mathrm{dm}^{-3}$ ) não foram observados sintomas foliares de toxidez deste elemento.

Com o aumento da disponibilidade de $\mathrm{P}$ no solo o teor de $\mathrm{K}$ na folha e na raiz reduziu, sendo a redução linear do teor foliar de $\mathrm{K}$ somente quando o solo não recebeu $\mathrm{K}$ e $\mathrm{N}$ (Figura 3B). Quando adicionados 50 e $100 \mathrm{mg} \mathrm{dm}^{-3}$ de $\mathrm{Ne} \mathrm{K}_{2} \mathrm{O}$, o teor foliar mínimo foi, respectivamente, de 12,4 e $14,5 \mathrm{~g} \mathrm{~kg}^{-1} \mathrm{de}$ $\mathrm{K}$, correspondente a 415 e $489 \mathrm{mg} \mathrm{dm}^{-3}$ de $_{\mathrm{P}_{2}} \mathrm{O}_{5}$. 
O teor mínimo radicular de $10,9 \mathrm{~g} \mathrm{~kg}^{-1}$ ocorreu na dose de $493 \mathrm{mg} \mathrm{dm}^{-3}$ de $\mathrm{P}_{2} \mathrm{O}_{5}$ (Figura 3B). A redução do teor foliar de $\mathrm{K}$ pode ser devido ao efeito de diluição, comprovado pelo aumento da produção de massa vegetal (Figura 2E e F), e diminuição da disponibilidade de $\mathrm{K}$ no solo (Figura 1B).

$\mathrm{O}$ teor de $\mathrm{N}$ na folha teve comportamento cúbico, sendo que o aumento a partir da dose de $464 \mathrm{mg} \mathrm{dm}^{-3} \mathrm{de}_{2} \mathrm{O}_{5}$ (Figura $3 \mathrm{C}$ ) pode estar relacionado ao efeito de concentração, visto que, próximo a essa dose ocorreu redução da produção de MSA (Figura 2E). Ao analisar somente o efeito das doses de NK sobre o teor foliar e radicular de N, observou-se aumento linear deste, obtendo-se, respectivamente, o teor máximo de 29,7 e $18,7 \mathrm{~g} \mathrm{~kg}^{-1}$ de $\mathrm{N}$ (Tabela 3).

$\mathrm{O} \mathrm{P}$ atuou de forma diferenciada sobre o teor de $\mathrm{Ca}$, reduzindo-o na folha e, aumentando-o na raiz (Figura 3D e E). Os teores foliares mínimos de 1,53, 1,35 e 1,46 $\mathrm{g} \mathrm{kg}^{-1}$ de Ca ocorreram, respectivamente, nas doses de 0,50 e $100 \mathrm{mg} \mathrm{dm}^{-3}$ de $\mathrm{N}$ e $\mathrm{K}_{2} \mathrm{O}$ e de 370,382 e $359 \mathrm{mg} \mathrm{dm}^{-3}$ de $_{2} \mathrm{O}_{5}$ (Figura $3 \mathrm{D})$. Esse resultado sugere duas hipóteses, uma relacionada à ação negativa de $\mathrm{NK}$ no teor de $\mathrm{Ca} \mathrm{e}$, a outra, referente à inibição da translocação do $\mathrm{Ca}$ da raiz para a parte aérea com o aumento das doses de P. A primeira é verificada pelo maior teor foliar de $\mathrm{Ca}$ (Figura 3D) e aumento linear do teor radicular de $\mathrm{Ca}$, na dose de $0 \mathrm{mg} \mathrm{dm}^{-3}$ de $\mathrm{N}$ e $\mathrm{K}_{2} \mathrm{O}$, quando comparado ao comportamento quadrático nas doses 50 e $100 \mathrm{mg} \mathrm{dm}^{-3}$ de $\mathrm{Ne} \mathrm{K}_{2} \mathrm{O}$ com as doses de $\mathrm{P}$ (Figura 3E). A segunda hipótese é que, mesmo com o aumento do teor de Ca nas raízes (Figura 3E) em consequência da maior disponibilidade de $\mathrm{Ca}$ no solo (Figura 1C), o aumento do teor de $\mathrm{P}$ na planta (Figura 3A) pode ter causado a redução do teor de Ca na folha (Figura 3D). Behling et al. (1989) e Horst et al. (1992) já haviam sugerido uma baixa eficiência de utilização de Ca em algumas espécies, causada pela inativação do mesmo, devida à ligação e, ou, à precipitação na forma de fosfato de cálcio.
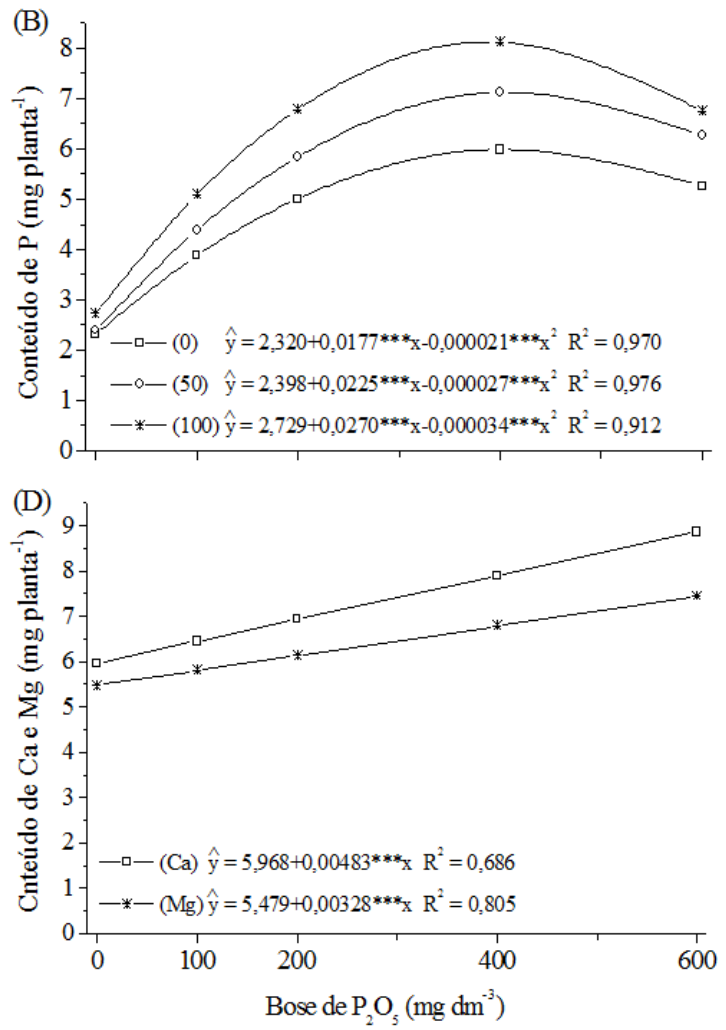

FIGURA 4: Composição química de plantas jovens de Ilex paraguariensis em função das doses de $\mathrm{P}$ e NK. Conteúdo de N (A), P (B), K (C) e Ca e Mg (D) na folha+raiz. **, *** significativo respectivamente a $1 ; 0,1 \% \mathrm{e}^{\text {ns }}$ não significativo.

FIGURE 4: Chemical composition of Ilex paraguariensis seedlings as affected by $\mathrm{P}$ and NK fertilization. Leaf and root contents of $\mathrm{N}(\mathrm{A}) ; \mathrm{P}(\mathrm{B}) ; \mathrm{K}(\mathrm{C})$ and $\mathrm{Ca}$ and $\mathrm{Mg}(\mathrm{D}) . * * * * *$ significant respectively at the; $1 ; 0,1 \%$ levels and ${ }^{\text {ns }}$ no-significant. 
Os resultados desse estudo indicam que a erva-mate, em condições de teores elevados de $\mathrm{P}$ no solo, poderia utilizar parte do $\mathrm{Ca}$ da raiz para formar compostos com o $\mathrm{P}$, como estratégia para evitar que altos teores de $\mathrm{P}$ nas folhas causem desordens nutricionais à planta. Isso merece uma investigação especial, já que precedentes na literatura com outras espécies pouco esclarecem o fato. Apesar de o Ca estar em nível adequado no solo, a sua interação com o P reduziu o seu teor foliar atingindo teores abaixo do que normalmente é verificado em mudas de erva-mate (REISSMANN et al., 1983; RADOMSKI et al., 1992), o que poderia limitar o crescimento das plantas.

Para o $\mathrm{Mg}$, de maneira geral, o teor foliar diminuiu com adição de doses de $\mathrm{P}$ (Tabela 3 ). $\mathrm{Na}$ raiz, o aumento linear do teor de $\mathrm{Mg}$ na dose de $0 \mathrm{mg} \mathrm{dm}{ }^{-3}$ de $\mathrm{N}$ e $\mathrm{K}_{2} \mathrm{O}$, a falta de significância na dose de $50 \mathrm{mg} \mathrm{dm}^{-3}$ de $\mathrm{N}$ e $\mathrm{K}_{2} \mathrm{O}$ e a redução do teor deste na dose de $100 \mathrm{mg} \mathrm{dm}^{-3}$ de $\mathrm{Ne} \mathrm{K}_{2} \mathrm{O}$, pode ser um indicativo do efeito de diluição de $\mathrm{Mg}$ com o aumento da produção de massa vegetal (Figura 2E e F). Cabe salientar que, apesar do Mg no solo estar em nível considerado baixo (SBCS, 2004) (Tabela 2), na dose de $\mathrm{P}\left(372 \mathrm{mg} \mathrm{dm}^{-3}\right.$ de $\left.\mathrm{P}_{2} \mathrm{O}_{5}\right)$, que maximizou a produção de MSA (Figura $2 \mathrm{E}$ ), o teor foliar de $\operatorname{Mg}\left(2,2 \mathrm{~g} \mathrm{~kg}^{-1}\right)$ foi superior ao do $\mathrm{Ca}\left(1,5 \mathrm{~g} \mathrm{~kg}^{-1}\right)$, mostrando que a erva-mate em condições de baixos níveis de $\mathrm{Mg}$ no solo é eficiente na sua absorção.

A influência das doses de $\mathrm{P}$ no teor de $\mathrm{Fe}$ nos compartimentos da planta foi bem distinta. Enquanto que na raizo teor de Fe aumentou até $1147,6 \mathrm{mg} \mathrm{kg}^{-1} \mathrm{na}$ dose de $331 \mathrm{mg} \mathrm{dm}^{-3}$ de $\mathrm{P}_{2} \mathrm{O}_{5}$, na folha, o teor deste reduziu linearmente com o aumento das doses de P (Figura 3F). De forma geral, a proporção entre o teor radicular/foliar de $\mathrm{Fe}$ variou de 10 a 21:1. A partir da dose de $400 \mathrm{mg} \mathrm{dm}^{-3}$ de $\mathrm{P}_{2} \mathrm{O}_{5}$ observou-se clorose internerval nas folhas jovens, sintomas típicos de deficiência de $\mathrm{Fe}$, induzido pelas altas doses de P. Assim, teores foliares de Fe abaixo de $50 \mathrm{mg} \mathrm{kg}^{-1}$ induzem sintomas de deficiência e podem limitar o crescimento da erva-mate. Sintomas semelhantes causados pelo alto nível de $\mathrm{P}$ no solo também foram verificados por Missio et al. (2004) em grápia. $\mathrm{O}$ declínio do teor de $\mathrm{Fe}$ na folha com o aumento das doses de $\mathrm{P}$, normalmente ocorre pela precipitação do $\mathrm{Fe}$ com o fosfato nos espaços intracelulares (ADAMS, 1980), possível estratégia da planta para evitar a toxidez de Fe na parte aérea.

Com exceção para o teor foliar de Mn e radicular de $\mathrm{Al}$ que aumentaram com as doses de $\mathrm{P}$, o teor foliar de $\mathrm{Cu}$ (Tabela 3) e $\mathrm{Zn}$ e, teor radicular de $\mathrm{Zn}$ (Figura 3H), Cu e Mn (Tabela 3) reduziram. Considerando a interação entre os nutrientes testados, nas doses de $\mathrm{P}_{2} \mathrm{O}_{5}$ para todas as doses de $\mathrm{N}$ e $\mathrm{K}_{2} \mathrm{O}$, o teor foliar mínimo de $\mathrm{Zn}$ e $\mathrm{Cu}$ variou respectivamente de 2,9 a 5,2 e 5,6 a $7,7 \mathrm{mg} \mathrm{kg}^{-1} \mathrm{e}$, o teor mínimo radicular de $\mathrm{Zn}$ de 22,2 a $32,1 \mathrm{mg} \mathrm{kg}^{-1}$. Tanto o teor de $\mathrm{Zn}$ quanto o de $\mathrm{Cu}$ na raiz foi superior ao da folha.

A hipótese mais aceita da interação antagônica do P sobre o teor de $\mathrm{Zn}$ e $\mathrm{Cu}$ na planta é que o desbalanço entre nutrientes na solução do solo dificulta a absorção destes. Mesmo quando a raiz absorve $\mathrm{Zn}$ e $\mathrm{Cu}$ em quantidades ideais, se houver na raiz altos teores de $\mathrm{P}$, pode ocorrer formação de compostos fosfatados pouco solúveis que dificilmente serão translocados para a parte aérea (KABATAPENDIAS e PENDIAS, 2000). Esta hipótese corrobora com os resultados deste trabalho, tanto pela redução do teor na raiz, quanto pela diferença de teores foliares e radiculares de $\mathrm{Zn}$ e $\mathrm{Cu}$, em função das doses de P.

Dentre os micronutrientes analisados, o Mn foi o único em que o teor radicular foi menor que o teor foliar (Tabela 3). Este comportamento se deve ao baixo transporte de $\mathrm{Mn}$ no floema, ocasionando seus menores teores obtidos em órgãos de reserva e raízes (KABATA-PENDIAS e PENDIAS, 2000). O máximo teor foliar de $\mathrm{Mn}\left(1244,7 \mathrm{mg} \mathrm{kg}^{-1}\right)$ na dose de $100 \mathrm{mg} \mathrm{dm}^{-3}$ de $\mathrm{N}$ e $\mathrm{K}_{2} \mathrm{O}$ situou-se acima dos demais micronutrientes, mostrando que a erva-mate pode acumular altos teores deste elemento, sem prejudicar seu desenvolvimento. Esta observação já havia sido ressaltada por Reissmann e Carneiro (2004), que indicaram sobre a possibilidade de que a erva-mate seja acumuladora de $\mathrm{Mn}$, ao constatarem teores foliares acima de $1000 \mathrm{mg} \mathrm{kg}^{-1}$.

Os conteúdos de N, P e K foram significativamente afetados pelas doses de $\mathrm{P}$ e de NK (Figuras 4A, B e C), sendo que para o conteúdo de $\mathrm{K}$ a interação apenas atuou nas doses 0 e $100 \mathrm{mg} \mathrm{dm}^{-3}$ de $\mathrm{N}$ e $\mathrm{K}_{2} \mathrm{O}$ (Figura 4C). Já os conteúdos de $\mathrm{Ca}$ e $\mathrm{Mg}$ foram afetados apenas pelas doses de $\mathrm{P}$ (Figura 4D). Houve alta correlação entre o crescimento e os conteúdos de $\mathrm{N}, \mathrm{P}, \mathrm{K}$ e $\mathrm{Mg}$ na folha, raiz e folha+raiz, com exceção da correlação entre o conteúdo de K na folha e folha+raiz com DC. O conteúdo da Ca nas folhas não se correlacionou significativamente com o crescimento (Tabela 4).

A semelhança das curvas do conteúdo de $\mathrm{N}$ e P na folha+raiz (Figura 4A e B) com as da HT, MSA e MST (Figura 2B, E e F) e a alta correlação entre elas (Tabela 4) são indicativos da maior contri- 
TABELA 4: Coeficientes de correlação linear simples (r) entre variáveis de crescimento e conteúdo de N, $\mathrm{P}, \mathrm{K}, \mathrm{Ca}$ e Mg na matéria seca de plantas jovens Ilex paraguariensis em função das doses de $\mathrm{P}$ e NK.

TABLE 4: Simple linear correlation coefficients ( $\mathrm{r}$ ) between growth variables and contents of N, P, K, Ca and $\mathrm{Mg}$ in dry matter of Ilex paraguariensis seedlings content with $\mathrm{P}$ and NK rates.

\begin{tabular}{|c|c|c|c|c|c|}
\hline \multirow{2}{*}{$\begin{array}{l}\text { Variáveis de } \\
\text { crescimento }^{1 /}\end{array}$} & \multicolumn{5}{|c|}{ Nutrientes } \\
\hline & $\mathrm{N}$ & $\mathrm{P}$ & $\mathrm{K}$ & $\mathrm{Ca}$ & $\mathrm{Mg}$ \\
\hline & \multicolumn{5}{|c|}{ Conteúdo foliar $\left(\mathrm{g}_{\text {planta }}{ }^{-1}\right)$} \\
\hline HT & $0,83^{* * *}$ & $0,96^{* * *}$ & $0,50 * * *$ & $-0,21^{\mathrm{ns}}$ & $0,30^{*}$ \\
\hline DC & $0,55^{* * *}$ & $0,81^{* * *}$ & $0,09^{\text {ns }}$ & $-0,06^{\mathrm{ns}}$ & $0,32 *$ \\
\hline MSF & $0,95^{* * *}$ & $0,93^{* * *}$ & $0,63 * * *$ & $-0,05^{\mathrm{ns}}$ & $0,48^{* *}$ \\
\hline MSR & $0,75^{* * *}$ & $0,90^{* * *}$ & $0,32 *$ & $-0,14^{\mathrm{ns}}$ & $0,42 * * *$ \\
\hline MST & $0,93 * * *$ & $0,95^{* * *}$ & $0,58 * * *$ & $-0,08^{\text {ns }}$ & $0,48^{* * *}$ \\
\hline VR & $0,78^{* * *}$ & $0,90^{* * *}$ & $0,38 * *$ & $-0,20^{\mathrm{ns}}$ & $0,37^{* *}$ \\
\hline \multirow[t]{2}{*}{$\mathrm{CR}$} & $0,70^{* * *}$ & $0,80^{* * *}$ & $0,35 * *$ & $-0,19^{\text {ns }}$ & $0,43^{* * *}$ \\
\hline & \multicolumn{5}{|c|}{ Conteúdo radicular $\left(\mathrm{g}_{\text {planta }}{ }^{-1}\right)$} \\
\hline HT & $0,84 * * *$ & $0,87^{* * *}$ & $0,65^{* * *}$ & $0,74 * * *$ & $0,48^{* * *}$ \\
\hline $\mathrm{DC}$ & $0,72 * * *$ & $0,74 * * *$ & $0,32 *$ & $0,68 * * *$ & $0,50^{* * *}$ \\
\hline MSF & $0,82 * * *$ & $0,88^{* * *}$ & $0,78^{* * *}$ & $0,76^{* * *}$ & $0,45^{* * *}$ \\
\hline MSR & $0,90^{* * *}$ & $0,94 * * *$ & $0,62 * * *$ & $0,82 * * *$ & $0,61 * * *$ \\
\hline MST & $0,86^{* * *}$ & $0,92 * * *$ & $0,76^{* * *}$ & $0,80^{* * *}$ & $0,50^{* * *}$ \\
\hline VR & $0,83^{* * *}$ & $0,87^{* * *}$ & $0,59 * * *$ & $0,81^{* * *}$ & $0,66^{* * *}$ \\
\hline \multirow[t]{2}{*}{$\mathrm{CR}$} & $0,76^{* * *}$ & $0,78^{* * *}$ & $0,57 * * *$ & $0,67 * * *$ & $0,55^{* * *}$ \\
\hline & \multicolumn{5}{|c|}{ Conteúdo na folha+raiz $\left(\right.$ g planta $\left.^{-1}\right)$} \\
\hline HT & $0,86^{* * *}$ & $0,95^{* * *}$ & $0,55^{* * *}$ & $0,29 *$ & $0,38^{* *}$ \\
\hline DC & $0,60^{* * *}$ & $0,80^{* * *}$ & $0,14^{\mathrm{ns}}$ & $0,38 * *$ & $0,40^{* * *}$ \\
\hline MSF & $0,96^{* * *}$ & $0,94 * * *$ & $0,69 * * *$ & $0,43^{* * *}$ & $0,53 * * *$ \\
\hline MSR & $0,81^{* * *}$ & $0,93^{* * *}$ & $0,40 * *$ & $0,39 * *$ & $0,52^{* * *}$ \\
\hline MST & $0,95^{* * *}$ & $0,96^{* * *}$ & $0,64 * * *$ & $0,43^{* * *}$ & $0,55^{* * *}$ \\
\hline VR & $0,81 * * *$ & $0,91^{* * *}$ & $0,44 * * *$ & $0,34 * *$ & $0,48^{* * *}$ \\
\hline $\mathrm{CR}$ & $0,73^{* * *}$ & $0,81^{* * *}$ & $0,42 * *$ & $0,18^{\mathrm{ns}}$ & $0,51^{* * *}$ \\
\hline
\end{tabular}

Em que: ${ }^{1}$ HT: altura total, DC: diâmetro do colo, CR: comprimento radicular, VR: volume radicular, MSF: matéria seca da folha, MSR: matéria seca radicular e MST: matéria seca total. ${ }^{*}, * *, * * *$ significativo respectivamente a $5 ; 1$; $0,1 \% \mathrm{e}^{\mathrm{ns}}$ não significativo.

buição positiva destes nutrientes para o crescimento da erva-mate. Esse resultado reforça a hipótese que a erva-mate é exigente em P (SANTIN et al., 2008) e também em $\mathrm{N}$.

Para o K, a grande diferença entre o conteúdo máximo de 36,1 e 71,4 mg planta-1 ${ }^{-1}$, respectivamente nas doses de 0 e $100 \mathrm{mg} \mathrm{dm}^{-3}$ de $\mathrm{N} \mathrm{e} \mathrm{K}_{2} \mathrm{O}$ (Figura 4C), mostra que se deve ter atenção especial com esse nutriente no solo. Isso fica evidente pela correlação significativa ( $r=0,78$, não demonstrada) entre o aumento do conteúdo de $\mathrm{K}$ na folha+raiz e a redução do teor de K no solo (Figura 1B).

$\mathrm{O}$ comportamento diferenciado entre $\mathrm{O}$ teor de $\mathrm{Ca}$ e $\mathrm{Mg}$ na folha e na raiz (Figura 3D e E; Tabela 3) e a ausência de correlação entre o conteúdo de $\mathrm{Ca}$ foliar e todas as variáveis de crescimento, aliados à característica calcífuga (REISSMANN e CARNEIRO, 2004), reforçam a hipótese da possível baixa exigência da erva-mate nesses nutrientes. Por outro lado, a alta correlação entre as variáveis de crescimento e o conteúdo de Ca radicular indica a importância desse nutriente no crescimento das raízes e pode ter refletido positivamente nas demais variáveis de crescimento (Tabela 4). Esse comportamento do $\mathrm{Ca}$ merece um estudo específico para maiores esclarecimentos. 


\section{CONCLUSÕES}

A erva-mate é exigente em $\mathrm{P}$, demonstrando o melhor crescimento quando o teor deste no solo se situa na faixa entre 18,5 e $28,6 \mathrm{mg} \mathrm{dm}^{-3}$.

$\mathrm{O}$ desequilíbrio entre nutrientes causado por altos teores de $\mathrm{P}$ no solo favorece a interação antagônica entre o teor de $\mathrm{P}$ com o de $\mathrm{Ca}$, $\mathrm{Mg}, \mathrm{Fe}, \mathrm{Cu}$ e $\mathrm{Zn}$ da folha, sendo que doses acima de $400 \mathrm{mg} \mathrm{dm}^{-3}$ de $\mathrm{P}_{2} \mathrm{O}_{5}$ causaram deficiência de $\mathrm{Fe}$ provocando clorose internerval nas folhas da erva-mate.

A ordem decrescente de macronutrientes mais exigidos e que mais contribuíram para $\mathrm{o}$ crescimento da erva-mate foi $\mathrm{P}>\mathrm{N}>\mathrm{K}>\mathrm{Mg}>\mathrm{Ca}$. Porém, para o crescimento de raiz a ordem foi $\mathrm{P}>\mathrm{N}>\mathrm{Ca}>\mathrm{K}>\mathrm{Mg}$.

A erva-mate cresce bem em solos com altos teores de $\mathrm{P}$, mas, a maximização do crescimento das plantas depende da boa disponibilidade de $\mathrm{N}, \mathrm{K}$ e Ca.

\section{AGRADECIMENTO}

À empresa Baldo S.A. de São Mateus do Sul e à UFPR - PR, que juntas, possibilitaram a realização deste trabalho.

\section{REFERÊNCIAS BIBLIOGRÁFICAS}

ABREU, C. A.; LOPES, A. S.; SANTOS, G. Micronutrientes. In: NOVAIS, R. F. et al. (Ed.). Fertilidade do solo. Viçosa: Sociedade Brasileira de Ciência do Solo, 2007. p. 645-736.

ADAMS, F. Interaction of phosphorus with other elements in soils and in plant. In: KHASAWNEH, F. E. et al. (Ed.) The role of phosphorus in agriculture. Madison: ASA, CSSA, SSSA, 1980. p. 655-680.

ALVES, A. C. et al. Exigências nutricionais em potássio, cálcio e magnésio do sorgo sacarino. Pesquisa Agropecuária Brasileira, Brasília, v. 23, n. 5, p. 529-536, maio. 1988.

ALVES, V. M. C. et al. Efeito da omissão de fósforo na absorção de nitrogênio por híbridos de milho (Zea mays, L.). Revista Ceres, Viçosa, v. 43, n. 248, p. 435-443, 1996.

BEHLING, J. P.; GABELMAN, W. H.; GERLOFF, G. C. The distribution and utilization of calcium by two tomato (Lycopersicon esculentum Mill.) lines differing in calcium efficiency when grown under low-Ca stress. Plant and Soil, Netherland, v. 113, p. 189-196, 1989.
BREMNER, J. M. Nitrogen total. In: SPARKS, D. L. Methods of soil analysis. Part 3. Madison: America Society of Agronomy, 1996. p. 1085-1121.

CARVALHO, P. E. R. Espécies arbóreas brasileiras. Colombo: Embrapa Florestas, 2003. 1039 p. v. 1.

DECHEN, A. R.; NACHTIGALL, G. R. Elementos requeridos à nutrição de plantas. In: NOVAIS, R. F. et al. (Ed.). Fertilidade do solo. Viçosa: Sociedade Brasileira de Ciência do Solo, 2007. p. 91-132. EMBRAPA. Manual de métodos de análise de solo. 2. ed. Rio de Janeiro: Embrapa, 1997. 212 p.

FAGERIA, N. K.; ARAÚJO, A. P.; STONE, L. F. Mudanças químicas na rizosfera. In: MELO, V. F.; ALLEONI, L. R. F. Química e mineralogia do solo. Viçosa: Sociedade Brasileira de Ciência do Solo, 2009. p. 161-186.

FERNANDES, L. A. et al. Crescimento inicial, níveis críticos de fósforo e frações fosfatadas em espécies florestais. Pesquisa Agropecuária Brasileira, Brasília, v. 35, n. 6, p. 1191-1198, jun. 2000.

FERREIRA, D. F. Sisvar: um programa para análises e ensino de estatística. Revista Científica Symposium, Lavras, v. 6, n. 2, p. 36-41, jul./dez. 2008.

FONSECA, J. A. da; MEURER, E. J. Inibição da absorção de magnésio pelo potássio em plântulas de milho em solução nutritiva. Revista Brasileira de Ciência do Solo, Viçosa, v. 21, n. 1, p. 47-50, 1997. GONÇALVES, J. L. M. et al. Cinética de adsorção de fósforo em solos de cerrados. Revista Brasileira de Ciência do Solo, Campinas, v. 9, n. 2, p. 107-111, 1985.

GONÇALVES, J. L. M. et al. Cinética de transformação de fósforo-lábil e não-lábil, em solos de cerrado. Revista Brasileira de Ciência do Solo, Campinas, v. 13, n. 1, p. 13-24, 1989.

HORST, W. J.; CURRLE, C.; WISSEMEIER, A. H. Differences in calcium efficiency between cowpea (Vigna unguiculata (L.) Walp.) cultivars. Plant and Soil, Netherland, v. 146, p.45-54, 1992.

JESCHKE, W. D. et al. Effects of P deficiency on assimilation and transport of nitrate and phosphate in intact plants of castor bean (Ricinus communis $\mathrm{L}$ ). Journal Experimental Botany, v. 48, n. 1 p. 95-91, Jan. 1997.

KABATA-PENDIAS, A.; PENDIAS, H. Trace elements in soils and plants. 3rd ed. Boca Raton, London: CRC Press, 2000. $331 \mathrm{p}$.

LAMBERS, H.; POORTER, H. Inherent variations in growth rate between higher plants: A search for physiological causes and ecological consequences. Advances in Ecological Research, San Diego, v. 
23, p.187-261, 1992.

LORENAGAN, J.F.; WEBB, M.J. Interaction between zinc and others nutrients affecting the growth of plant. In: ROBSON, A. D. Zinc in soils and plants. Dordrecht: Kluwer Academic Publishers, 1993, p. 119-134

LUCA, E. F. de. et al. Eficiência de absorção e utilização de fósforo $\left({ }^{32} \mathrm{P}\right)$ por mudas de eucalipto e arroz. Scientia Agrícola, Piracicaba, v. 59, n. 3, p. 543-547, 2002.

MACCARI, JR. A.; MAZUCHOWSKI, J. Z. Produtos alternativos e desenvolvimento da tecnologia industrial na cadeia produtiva da ervamate. Curitiba: Câmara Setorial da Cadeia Produtiva da Erva-Mate Paraná MCT/CNPq/PROJETO PADCT Erva-Mate. Curitiba. 2000. 176 p.

MARSCHNER, H. Mineral nutrition of higher plants. 2nd ed. London, Academic Press, 1995. $889 \mathrm{p}$.

MARTINS, A. P. L.; REISSMANN, C. B. Material vegetal e as rotinas laboratoriais nos procedimentos químico-analíticos. Scientia Agraria, Curitiba, v. 8, n. 1, p. 1-17, 2007.

MISSIO, E. L. et al. Exigências nutricionais da grápia ao fósforo e enxofre em Argissolo Vermelho distrófico arênico: Efeito da adubação no crescimento. Ciência Rural, Santa Maria, v. 34, n. 4, p.1051-1057, jul./ ago. 2004.

MORTVEDT, J. J.; KHASAWNEH, F. E. Effects of growth responses on cationic relationships in plants. Soil Science, Baltimore, v.141, n. 3, p. 200-207, 1986.

NICOLOSO, F. T. et al. Exigências nutricionais da grápia em Argissolo Vermelho distrófico arênico: (II) Efeito da adubação NPK no teor de nutrientes nos tecidos. Ciência Rural, Santa Maria, v. 37, n. 2, p. 372-380, mar./abr. 2007.

NOVAIS, R. F.; SMYTH, T. J. Fósforo em solo e planta em condições tropicais. Viçosa, UFV, DPS. 1999. $399 \mathrm{p}$.

OLSEN, G. M. Interacciones de los micronutrientes. In: MORTVEDT, J. J.; GIORDANO, P. M.; LINDSAY, W. L. (Ed.). Micronutrientes en agricultura. México: AGT, 1983. p. 317-348.

RADOMSKI, M. I. et al. Avaliação dos teores de macro e micronutrientes em folhas jovens e velhas de erva-mate nativa. Revista do Instituto Florestal, São Paulo, v. 4, p. 453-456, 1992. (Edição Especial). REDDY, K. P.; SAXENA, M. C.; PAL, U. R. Effect of iron and manganese on in ${ }^{65} \mathrm{Zn}$ absorption and translocation in soybean seedlings. Plant and Soil, Netherland, v. 49, p. 409-415, 1978.
REISSMANN, C. B. et al. Bio-elementos em folhas e hastes de erva-mate (Ilex paraguariensis St. Hill.) sobre cambisolos na região de Mandirituba - PR. Floresta, Curitiba, v. 14. n. 2, p. 49-54, 1983.

REISSMANN, C. B.; CARNEIRO, C. Crescimento e composição química da erva-mate (Ilex paraguariensis St. Hil.), transcorrido oito anos de calagem. Floresta, Curitiba, v. 34, n. 3, p. 281386, 2004.

ROLIM NETO, F. C. et al. Adsorção de fósforo, superfície especifica atributos mineralógicos em solos desenvolvidos de rochas vulcânicas do Alto Paranaíba (MG). Revista Brasileira de Ciência do Solo, Viçosa, v. 28, n. 6, p. 953-964, 2004.

RUFTY JR. T. W.; MACROWN, C. T.; ISRAEL, D. W. Phosphates stress effects on assimilation of nitrate.

Plant Physiology, Illinois, n. 94, p. 328-333, 1990.

SANTIN, D. et al. Nitrogênio, fósforo e potássio no crescimento de mudas de erva-mate. Scientia Agraria, Curitiba, v. 9, n. 1, p. 59-66, 2008.

SBCS - Sociedade Brasileira de Ciência do Solo. Manual de adubação e calagem para os Estados do Rio Grande do Sul e de Santa Catarina. Comissão de química e fertilidade do solo. 10. ed. Porto Alegre. 2004, 400 p.

SHUMAN, L. M. Effect of phosphorus level on extractable micronutrients and their distribution soil fractions. Soil Science Society of America Journal, Madison, v. 52, p. 136-141, 1988.

SHUMAN, L.M. Mineral nutrition. In:WILKINSON, R. E., ed. Plant-environment interactions. New York, Marcel Dekker, 1994. p. 149-182.

SOUZA, J. L. M. et al. Teores de nutrientes foliares em plantas de erva-mate em função da posição e orientação geográfica da copa, em Guarapuava-PR. Scientia Agraria, Curitiba, v. 9, n. 1, p. 49-58, 2008. VENTURIN, N. et al. Adubação mineral do angicoamarelo (Peltophorum dubium (Spreng.) Taub.). Pesquisa Agropecuária Brasileira, Brasília, v. 34, n. 3, p. 441-448, mar. 1999.

VENTURIN, N. et al. Fertilização de plântulas de Copaifera langsdorffii Desf. (óleo copaíba). Cerne, Lavras, v. 2, n. 2, p. 1-17, 1996.

WISNIEWSKI, C. et al. Exportação de biomassa e macronutrientes com a primeira poda de formação da erva-mate na região de Pinhais-PR. Revista do Setor de Ciências Agrárias, Curitiba, v. 15, n. 2, p. 179186, 1996.

ZONTA, E. et al. O sistema radicular e suas interações com o ambiente edáfico. In: FERNANDES, M. S. Nutrição mineral de plantas. Viçosa: Sociedade Brasileira de Ciência do Solo, 2006. p. 07-52. 